\title{
Análise do gene ACTN3 na prática esportiva de alto rendimento: uma revisão narrativa
}

\author{
Analysis of the ACTN3 gene in high performance sports practice: a narrative review \\ Análisis del gen ACTN3 en la práctica deportiva de alto rendimiento: una revisión narrativa
}

Recebido: 24/10/2021 | Revisado: 04/11/2021 | Aceito: 09/11/2021 | Publicado: 13/11/2021

\author{
Danieli Amorim Camilo \\ ORCID: https://orcid.org/0000-0002-6298-1882 \\ Faculdade de Santa Bárbara do Oeste, Brasil \\ E-mail: danielicamilo99@gmail.com \\ Leonardo Emmanuel de Medeiros Lima \\ ORCID: https://orcid.org/0000-0003-3182-9316 \\ Universidade São Judas Tadeu, Brasil \\ E-mail: leonardolimadocente@gmail.com \\ Gildiney Penaves de Alencar \\ ORCID: https://orcid.org/0000-0002-5177-495X \\ Universidade Federal de Mato Grosso do Sul, Brasil \\ Centro Universitário da Grande Dourados, Brasil \\ E-mail: gildiney.gpa@gmail.com \\ Raphael de Souza Cosmo \\ ORCID: https://orcid.org/0000-0001-7095-1782 \\ Universidade Federal de Mato Grosso do Sul, Brasil \\ Centro Universitário da Grande Dourados, Brasil \\ E-mail: rafa-mig@hotmail.com \\ Diego Duarte Marques de Oliveira \\ ORCID: https://orcid.org/0000-0003-0363-8942 \\ Universidade Federal de Mato Grosso do Sul, Brasil \\ E-mail: diegooduarte@ hotmail.com \\ Rodrigo Pereira da Silva \\ ORCID: https://orcid.org/0000-0002-1020-3392 \\ Universidade Federal de São Paulo, Brasil \\ Universidade Metropolitana de Santos, Brasil \\ Faculdade Praia Grande, Brasil \\ E-mail: profrodrigosilva@unimes.br \\ Dilmar Pinto Guedes Junior \\ ORCID: https://orcid.org/0000-0001-5430-4489 \\ Universidade Metropolitana de Santos, Brasil \\ Universidade Santa Cecília, Brasil \\ E-mail: dilmarpintoguedesjr@gmail.com \\ Aylton Figueira Junior \\ ORCID: https://orcid.org/0000-0001-8069-2366 \\ Universidade Nove de Julho, Brasil \\ Universidade São Judas Tadeu, Brasil \\ E-mail: aylton.junior@saojudas.br \\ José Garcia de Brito-Neto \\ ORCID: http://orcid.org/0000-0002-0705-6790 \\ Faculdade Nova Esperança, Brasil \\ E-mail: jgarcia.academico@hotmail.com \\ Roberto Moriggi Junior \\ ORCID: http://orcid.org/0000-0003-0844-7985 \\ Universidade Estadual de Campinas, Brasil \\ E-mail: juniormorigg@gmail.com
}

\section{Resumo}

Objetivo: Analisar o gene ACTN3 na prática esportiva de alto rendimento, bem como verificar a relação com o desempenho na modalidade específica e a influência do gene ACTN-3 sobre a caracterização das fibras musculares. Metodologia: Trata-se de um estudo de revisão narrativa da literatura, que analisou artigos publicados em língua portuguesa e/ou inglesa, entre os anos 1995 e 2020, encontrados na plataforma de pesquisa Google Acadêmico, selecionados a partir das palavras-chave, sinônimos e descritores "genética", "polimorfismo", "performance" e "actn3". Foram incluídos estudos com texto completo disponível em meio online, de forma gratuita, que forneciam informações sobre genética humana, o polimorfismo do gene ACTN3, a influência da genética no desempenho esportivo e os tipos de fibras musculares e sua intervenção no esporte, totalizando 41 artigos. Resultados: A análise 
resultou numa categorização, separada por cinco temáticas que devem ser consideradas dentro da prescrição e prática esportiva de alto rendimento: a) Individualidade biológica: genética no esporte; b) Actina; c) Polimorfismo genético; d) Genótipo ACTN3 RR, XX, RX; e) O polimorfismo R577X do gene ACTN3: relação da genética com o tipo de fibra muscular. Considerações Finais: A expressão do gene ACTN3 favorece o desempenho esportivo de atletas que exercem força/velocidade. Pessoas com o genótipo mutante possuem maior desempenho quando se trata de esportes de resistência aeróbia. Dessa forma, além dos fatores intrínsecos, os fatores extrínsecos precisam ser constantemente manipulados, como o treinamento adequado, rotina de descanso e alimentação, indispensáveis para uma boa performance.

Palavras-chave: Genética; Polimorfismo; Performance; ACTN3.

\begin{abstract}
Objective: To analyze the ACTN3 gene in high performance sports, as well as to verify the relationship with performance in the specific sport and the influence of the ACTN-3 gene on the characterization of muscle fibers. Methodology: This is a study of narrative literature review, which analyzed articles published in Portuguese and/or English, between 1995 and 2020, found on the Google Academic search platform, selected from the keywords, synonyms and descriptors "genetic", "polymorphism”, “performance" and "actn3". Full-text studies available online, free of charge, were included, providing information on human genetics, the ACTN3 gene polymorphism, the influence of genetics on sports performance and the types of muscle fibers and their intervention in sport, totaling 41 articles . Results: The analysis resulted in a categorization, separated by five themes that should be considered within the prescription and practice of high performance sports: a) Biological individuality: genetics in sport; b) Actin; c) Genetic polymorphism; d) ACTN3 RR, XX, RX genotype; e) The R577X polymorphism of the ACTN3 gene: relationship between genetics and muscle fiber type. Final Considerations: The expression of the ACTN3 gene favors the sports performance of athletes who exercise strength/speed. People with the mutant genotype perform better when it comes to aerobic endurance sports. Thus, in addition to the intrinsic factors, the extrinsic factors need to be constantly manipulated, such as adequate training, rest and feeding routine, which are essential for a good performance.
\end{abstract}

Keywords: Genetics; Polymorphism; Performance; ACTN3.

\title{
Resumen
}

Objetivo: Analizar el gen ACTN3 en deportes de alto rendimiento, así como verificar la relación con el rendimiento en el deporte específico y la influencia del gen ACTN-3 en la caracterización de las fibras musculares. Metodología: Se trata de un estudio de revisión de literatura narrativa, que analizó artículos publicados en portugués y / o inglés, entre 1995 y 2020, encontrados en la plataforma de búsqueda Google Academic, seleccionados entre las palabras clave, sinónimos y descriptores "genética", "polimorfismo", “rendimiento" y "actn3". Se incluyeron estudios de texto completo disponibles online, gratuitos, que aportan información sobre la genética humana, el polimorfismo del gen ACTN3, la influencia de la genética en el rendimiento deportivo y los tipos de fibras musculares y su intervención en el deporte, totalizando 41 artículos. Resultados: El análisis resultó en una categorización, separados por cinco temas que deben ser considerados dentro de la prescripción y práctica de deportes de alto rendimiento: a) Individualidad biológica: genética en el deporte; b) actina; c) polimorfismo genético; d) genotipo ACTN3 RR, XX, RX; e) El polimorfismo R577X del gen ACTN3: relación entre la genética y el tipo de fibra muscular. Consideraciones finales: La expresión del gen ACTN3 favorece el rendimiento deportivo de los deportistas que ejercen fuerza / velocidad. Las personas con el genotipo mutante se desempeñan mejor cuando se trata de deportes de resistencia aeróbica. Así, además de los factores intrínsecos, es necesario manipular constantemente los factores extrínsecos, como el entrenamiento adecuado, el descanso y la rutina de alimentación, que son fundamentales para un buen desempeño.

Palabras clave: Genética; Polimorfismo; Rendimiento; ACTN3.

\section{Introdução}

A preparação física de atletas envolve uma rotina alimentar planejada, treinamentos específicos para a modalidade em questão e acompanhamento psicológico, além do descanso adequado (Pasqua, Artioli, Pires, \& Bertuzzi, 2011; Paiva, \& Carlesso, 2018). Entretanto, muitas vezes com a mesma rotina, atletas demonstram melhores respostas perante outros, possivelmente devido a fatores intrínsecos, como os aspectos genéticos (Hartl, 2008).

Há evidências que alguns polimorfismos de DNA provavelmente possam ter relação com a progressão do atleta no esporte. De acordo com Lima et al., (2006, p. 8), os polimorfismos são caracterizados por “variações na sequência de DNA que podem criar ou destruir sítios de reconhecimento de enzimas de restrição e parecem estar associados a apenas uma base" e 
pode ocasionar a alteração de características do indivíduo, presente em menor quantidade na população (Trindade, Rodrigues, Rodrigues, \& Almeida, 2017; Zonatto, 2018).

A literatura aponta quatro tipos de gene da proteína $\alpha$-actinina, sendo elas: ACTN1, ACTN2, ACTN3 e ACTN4 (Pasqua, Artioli, Pires, \& Bertuzzi, 2011). Em destaque temos o gene ACTN3, o qual é responsável pela produção da proteína alfa-actina 3 ( $\alpha$-actinina3), encontrado apenas em músculos esqueléticos, especificamente em fibras de contração rápida (tipo II), responsáveis por maior geração de força (Druzhevskaya, Ahmetov, Astratenkova, \& Rogozkin, 2008).

O polimorfismo do gene ACTN3 tem relação com a caracterização do tipo de fibras musculares, capaz de interferir diretamente no desempenho físico em determinadas modalidades (Zonatto, 2018). Ou seja, genes que possuem a diferenciação em sua sequência de base, influenciam na expressão de proteínas, podendo assim, modificar as características da contração muscular (Farias, Barroso, Cavalcante, \& Parente, 2017).

Este trabalho tem relevância ao esporte por mostrar a importância das características genéticas que fazem a diferença na performance esportiva, seja uma vantagem ou desvantagem, podendo interferir até mesmo na prevenção de lesões relacionadas ao excesso de treinamento, consequentemente prolongando a vida do atleta dentro do esporte. Além disso, possuindo o mapeamento genético de jovens e crianças, há grande probabilidade de influenciar na carreira do atleta de elite, uma vez que o mapeamento pode ser certeiro quando se trata de melhor desempenho na modalidade (Bueno Junior, \& Pereira, 2010; Pasqua, Artioli, Pires, \& Bertuzzi, 2011; Netto, 2014; Farias, Barros, Cavalcante, \& Parente, 2017).

Nesse sentido, este trabalho foi realizado com o objetivo de analisar o gene ACTN3 na prática esportiva de alto rendimento, bem como verificar a relação com o desempenho na modalidade específica e a influência do gene ACTN-3 sobre a caracterização das fibras musculares em comparação a outros atletas que não possuem a genética compatível com o esporte praticado.

\section{Metodologia}

Trata-se de um estudo de revisão narrativa da literatura, a qual aborda sobre a relação entre a genética, tipos de fibra muscular e rendimento esportivo de atletas, segundo recomendações de Rother (2007). Fizeram parte desse trabalho artigos publicados em língua portuguesa e/ou inglesa, entre os anos 1995 e 2020, encontrados na plataforma de pesquisa Google Acadêmico.

A busca pelos textos foi realizada por dois revisores independentes e às cegas, a partir das palavras-chave, sinônimos e Descritores em Ciências da saúde (DeCS) e do Medical Subject Headings (MeSH), combinados por meio do operador booleano AND da seguinte forma: "genética" AND "polimorfismo" AND "performance" AND "actn3".

Foram incluídos estudos com texto completo disponível em meio online, de forma gratuita, que forneciam informações sobre genética humana, o polimorfismo do gene ACTN3, a influência da genética no desempenho esportivo e os tipos de fibras musculares e sua intervenção no esporte, totalizando 41 artigos.

Após realizada a seleção do material, o conteúdo foi organizado de forma narrativa, de maneira a proporcionar uma visão ampliada do assunto, separados por cinco temáticas: a) Individualidade biológica: genética no esporte; b) Actina; c) Polimorfismo genético; d) Genótipo ACTN3 RR, XX, RX; e) O polimorfismo R577X do gene ACTN3: relação da genética com o tipo de fibra muscular.

\section{Resultados e Discussão}

\subsection{Individualidade biológica: genética no esporte}

O genoma é uma denominação associada ao conjunto de informações hereditárias expressas na cadeia do DNA. As informações hereditárias são separadas dentro do DNA através de subunidades chamadas genes. Os genes armazenam e 
codificam as informações hereditárias, após esse processo, são produzidas outras proteínas, dando origem a formação das células, órgãos e tecidos do organismo, tornando cada ser humano único, com informações individuais. Os genes formam um filamento no interior da estrutura denominada cromossomo, o corpo humano possui 46 cromossomos divididos em 23 pares (Borges-Osório, \& Robinson, 2013).

O DNA humano é composto por aproximadamente 3,1 bilhões de pares de bases nitrogenadas. As bases nitrogenadas (A: adenina; G: guanina; C: citosina; T: timina) são divididas em aproximadamente 20-25 mil genes que, após serem transcritos, dão origem a uma proteína específica. Algumas dessas proteínas, em sua transcrição, sofrem mutação, não possuindo o potencial da expressão do gene (Rebbeck, Spitz, \& Wu, 2004). A identificação da variação genética juntamente com a rotina de treinamento individualizada para um atleta pode influenciar na performance em várias modalidades esportivas, possibilitando também a identificação de talentos em esportes específicos.

Cada gene ocupa diferentes posições no cromossomo, que recebem o nome de lócus (Wood, 1995; Borges-Osório, \& Robinson, 2013). Os genes possuem variantes que são conhecidas como alelos, sendo assim, é correto afirmar que o alelo reside em lócus específicos. Desta forma, alelos são diferentes formas de um mesmo gene, podendo sofrer mutações. Muitas vezes, diferentes alelos resultam em diferentes características fenotípicas, como por exemplo, a pigmentação da pele (Strachan, \& Read, 2016). Quando o cromossomo possui o mesmo alelo em um lócus específico, são chamados de homozigotos, já na situação que possuem alelos diferentes, são chamados de heterozigotos, essas características estão relacionadas a individualidade biológica (Wood, 1995).

A individualidade biológica é a diferenciação da mesma espécie, ou seja, são as características individuais de cada pessoa, as tornando diferentes umas das outras (Tubino, 1979; Guimarães, Oliveira, Rassi, Valadão, \& Borges Júnior, 2014). Quando se trata de prescrição de treinamento, principalmente para atletas é indispensável analisar e respeitar a individualidade biológica de cada um para um bom planejamento esportivo, e cada indivíduo precisa ser tratado de forma única, levando em consideração as características físicas, desenvolvimento perante os treinos, intensidade dos exercícios, além da sua responsividade fisiológica frente os estímulos do treinamento esportivo (Bompa, 2002; Alencar, Gonçalves, Lima, \& Souza, 2017; Alencar, 2018; Paiva et al., 2019).

Ao ter conhecimento da sensibilidade de um indivíduo perante os estímulos, fator conhecido como responsividade fisiológica, o treinador deve garantir o controle da função saudável da musculatura do atleta, visando a prevenção do excesso de carga de treinamento (Abreu, Leal-Cardoso, \& Ceccatto, 2017). Isso diminui as chances de expor o atleta aos riscos de lesões e fadigas musculares, além de ser possível controlar o crescimento muscular de acordo com a necessidade demandada pelo esporte em questão, podendo manter, diminuir ou aumentar estímulos durante o treinamento (Alves, Costa, \& Samulski, 2006).

O planejamento do treinamento quando totalmente individualizado, ou seja, voltado para as necessidades do atleta, fornece ótima progressão na performance, pois através das características únicas, destacam-se aspectos negativos e positivos, que quando filtrados, são direcionados por meio de métodos específicos, é possível corrigi-los ou potencializa-los caso haja necessidade (Bompa, 2002).

O mapeamento genético de atletas de elite se torna um grande benefício para a identificação da melhor estratégia para treinamento (Yang et al., 2003). Um exemplo de vantagem genética é a deficiência da expressão do gene ACTN3 em indivíduos que praticam esportes de resistência, verificando que há influência na atividade enzimática metabólica no músculo esquelético, mudando as propriedades das fibras rápidas, deixando-as caracterizadas como fibras de contração lenta (MacArthur, \& North, 2005; MacArthur et al., 2007). O alelo nulo do ACTN3 (o polimorfismo R577X) está muito presente no genoma de atletas de resistência quando comparado com atletas de potência (Tanisawa et al., 2020). 
Deve-se levar em consideração não somente o genótipo do indivíduo como também o fenótipo. Fatores extrínsecos como o ambiente em que o indivíduo se desenvolveu faz parte da sua caracterização, a qual é a soma de questões intrínsecas (genótipo) e extrínsecas (fenótipo) (Tubino, 1979; Silva, Justina, Scheifele, \& Schneider, 2020). Todos os seres humanos possuem a mesma base genética, porém, atletas de elite podem apresentar variações em códigos de genes específicos devido a influência do fenótipo induzido através da performance física (Dias, Pereira, Negrão, \& Krieger, 2007).

Vale ressaltar que não só a base genética deve ser responsabilizada pelo sucesso atlético, e sim, compreender toda construção genética do desempenho atlético humano, além do amplo fenótipo do esporte relacionadas ao exercício, que é um desafio devido à grande complexidade (MacArthur et al., 2007). Desta forma, será abordado as possíveis influências da genética perante a performance esportiva.

\subsection{Actina}

O organismo humano é constituído por diversas estruturas proteicas, uma delas é a actina, que possui grande importância no processo contrátil muscular (Bray et al., 2009). Independentemente do tipo de fibra, a musculatura é composta por miofibrilas, mais afundo encontramos os sarcômeros, estrutura responsável pela contração muscular (Figura 1). Para que ocorra a contração, há o encurtamento dos sarcômeros, cuja ação é acarretada pela interação das proteínas actina e miosina (Scott, Stevens, \& Binder-Macleod, 2001).

Figura 1 - Estruturas no interior do sarcômero.

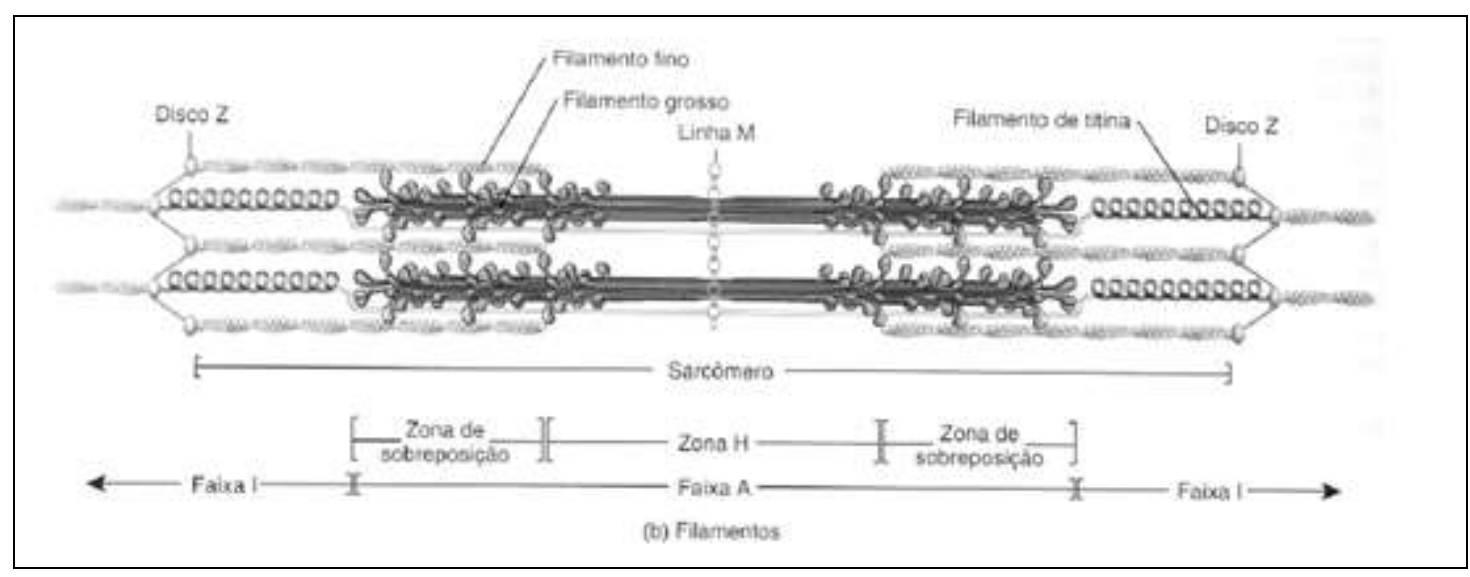

Fonte: Kasten (2013).

Na construção da proteína actina, existem outras proteínas que possuem importantes funções, o grupo predominante da composição da actina é denominado $\alpha$-actininas (ou alfa-actinina) (Bray et al., 2009). As $\alpha$-actininas interagem com uma variedade de estruturas, suas funções são sinalizadoras e metabólicas, tendo maior importância para as interações ocorrentes no sarcômero (Sjöblom, Salmazo, \& Djinović-Carugo, 2008).

A actinina (ACTN) possui quatro tipos de gene (ACTN1, ACTN2, ACTN3 e ACTN4), porém, apenas os genes ACTN2 e ACTN3 se expressam na musculatura esquelética humana. O ACTN2 está presente no músculo cardíaco, em todas as fibras musculares esqueléticas e no cérebro, enquanto o gene ACTN3 se expressa em pequena quantidade no cérebro e apresenta maior frequência em fibras musculares esqueléticas de contração rápida (tipo II), considerada a principal responsável pela geração de alta força contrátil, tornando sua identificação de extrema importância, sobretudo em esportes que possuem a potência muscular como principal variável (Berman, \& North, 2010).

A titina é uma longa proteína também encontrada no sarcômero, fixada pela proteína $\alpha$-actinina3. Esta longa proteína presente na linha Z, faz parte do processo de contração muscular, tendo como função preservar a manutenção e estabilidade do 
aparato contrátil durante contrações intensas das fibras do tipo II devido ao seu alto potencial elástico. As titinas agem como uma "mola", regulando o comprimento do sarcômero, ajustando bilateralmente a tensão da contração (Castro-Ferreira, FontesCarvalho, Falcão-Pires, \& Leite-Moreira, 2011).

\subsection{Polimorfismo genético}

Alguns indivíduos apresentam características genéticas diferentes da maioria dos outros seres, essa diferenciação é causada pelo chamado polimorfismo genético (Henesy et al., 2012). A hereditariedade é a transferência de informações de um DNA para formação de outro através do RNA mensageiro e, durante a transcrição das informações, pode naturalmente ocorrer uma mutação genética, alterando as funções de determinadas características dos genes, chamada de polimorfismo (Pimenta, 2012).

A mutação gênica ocorre devido à modificação de um gene específico, podendo haver a substituição, perda ou adição de uma única base nitrogenada. Existem alguns tipos e efeitos da mutação: a mutação selvagem (quando há codificação da proteína), a pontual (pode prejudicar ou criar uma nova função para proteína), a silenciosa (não afeta a proteína) e a nula (não ocorre a expressão da proteína) (Borges-Osório, \& Robinson, 2013). O polimorfismo de um gene pode causar alteração na expressão da característica do indivíduo, nesse caso pode ter influência positiva ou negativa no organismo do atleta (Pasqua, Artioli, Pires, \& Bertuzzi, 2011).

O gene ACTN3, quando funcional, permite que a $\alpha$-actinina exerça como função a regulação do processo contrátil, o controle do metabolismo energético e também a determinação do tipo de fibra muscular. Já o polimorfismo desse gene, ou seja, a mutação em uma de suas bases nitrogenadas, é capaz de influenciar na precisão e eficiência da contração das fibras musculares rápidas, sendo assim, atinge diretamente no desempenho físico do atleta, dependendo de sua modalidade esportiva em questão (Vincent et al., 2007).

O papel do gene ACTN3 na determinação da distribuição do tipo de fibra muscular comprova a influência positiva entre o genótipo ACTN3 com a quantidade de fibras glicolíticas rápidas (IIb) (Berman, \& North, 2010). O processo de determinação do tipo de fibra acontece, pois ocorre a ligação de ACTN3 com a calsarcina e calcineurina que, ao se interagirem, promovem a formação de fibras de contração rápida (Vincent et al., 2007). No que tange a predisposição dos tipos de fibra, visto que o gene ACTN3 induz a quantidade de fibras rápidas (IIb), esse passa a ter ligação direta com a performance, como por exemplo, de forma positiva para indivíduos que precisam de força durante o esporte e possuem a expressão do gene ACTN3 (Zonatto, 2018).

A deficiência do gene ACTN3, faz com que o ACTN2 substitua seu papel, porém, a afinidade do ACTN2 com a titina altera a estabilidade do sarcômero, ou seja, o ACTN2 não possui a função tão eficiente quanto o ACTN3. Sendo assim, modifica as propriedades elásticas da estrutura, prejudicando a precisão da contração em alta intensidade, alterando também as respostas químicas das proteínas no sarcômero, deixando as fibras musculares do tipo II com características mais oxidativas (Pasqua et al., 2011).

Estas alterações estão relacionadas a melhor performance em indivíduos que possuem a expressão do gene ACTN3 perante as atividades de força (Lek, \& North, 2010). Por outro lado, o polimorfismo do ACTN3, faz com que a proteína não seja expressa pelo gene, o que passa a ter relação com uma menor produção de força, possuindo menor diâmetro da fibra muscular de contração rápida, em contrapartida, possui aumento da eficiência metabólica do músculo esquelético (Druzhevskaya, Ahmetov, Astratenkova, \& Rogozkin, 2008). 


\subsection{Genótipo ACTN3 RR, XX, RX}

O ACTN3 está contido no cromossomo 11, em que a mutação ocorre através da troca de uma citosina por uma timina na posição (nucleotídeo) 1.747 do éxon 16. Sendo assim, no aminoácido 577, a arginina (R) é substituída por um stop codon (X). Os stop códons são nucleotídeos dentro do RNA mensageiro, que sinalizam a terminação da tradução da proteína, resultando em uma proteína não funcional (Figura 2). Esse polimorfismo resulta em dois alelos diferentes do gene ACTN3, o alelo 577R, sendo ele um alelo funcional, e o alelo mutante, denominado 577X (MacArthur, \& North, 2005). Desta maneira, o gene mutante XX ocasiona total ausência da expressão da proteína ACTN3 no músculo esquelético, fazendo com que o ACTN2 compense essa ausência (Scott, Stevens, \& Binder-Macleod, 2001; Cieszczyk, Sawczuk, Maciejewska-Karlowska, \& Ficek, 2012).

Figura 2 - Especificação do cromossomo 11.

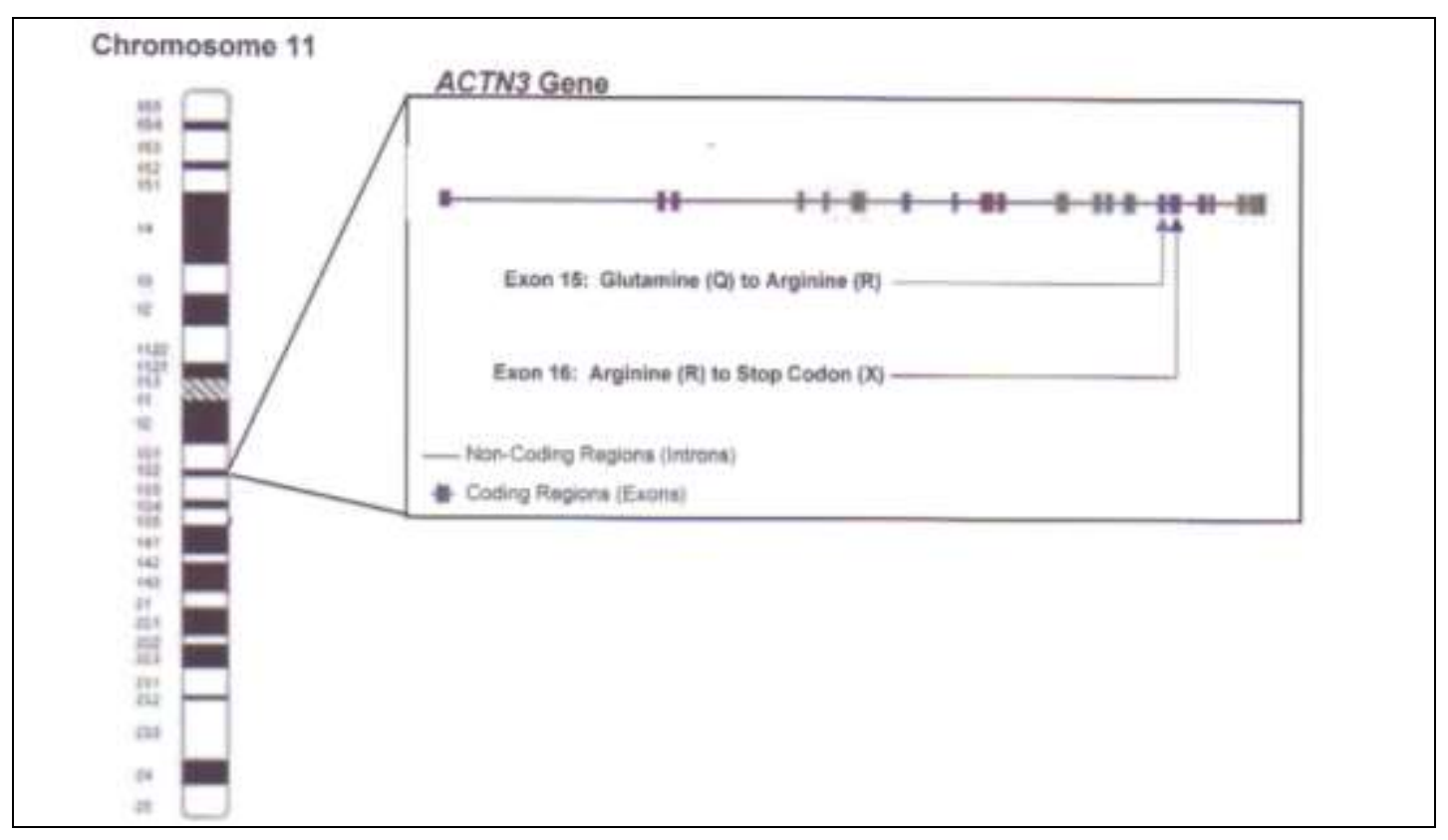

Fonte: Nesser (2009).

Indivíduos que dispõem de ambos os alelos polimórficos, homozigotos (genótipo XX) possuem defasagem total de ACTN3. Já indivíduos heterozigotos (genótipo RX), ou que possuem um alelo funcional (alelo R) e um alelo polimórfico (alelo X), apresentam uma redução na quantidade de ACTN3 (Zonatto, 2018).

Essa falta da atividade proteica ocasiona redução da atividade de glicogênio-fosforilase, alterando as vias de obtenção de energia de glicolítica para oxidativa. Indivíduos homozigotos (XX) possuem o gene ACTN3 sendo não funcional. Quando não há expressão da proteína $\alpha$-actinina-3, o organismo aumenta a produção da $\alpha$-actinina 2 , esta que supre a falta, porém não tão eficaz para a contração rápida tanto quanto a $\alpha$-actinina 3. O indivíduo que apresenta a mutação completa, ou seja, o alelo XX realiza menor atividade anaeróbia da quebra do glicogênio, ficando comprometida pela falta do ACTN3. Como consequência, o metabolismo da fibra muscular detém características oxidativas (Berman, \& North, 2010).

As variações 577X e 577R do gene ACTN3 nos humanos se originam dos antepassados primitivos. Houve uma seleção natural de acordo com o ambiente específico, visto que em alguns, predominava a necessidade de maior persistência a caça, geração de força e disputa por território, tornando-os com maior ambição pela sobrevivência, ocasionando a evolução dos genótipos (Ahmetov et al., 2013).

O ACTN3 R tem relação com o aumento dos níveis de testosterona de atletas. Isso só é possível, pois ocorre interação 
das a $\alpha$-actinas com a calcineurina, o que acarreta sua a inibição, assim potencializando a produção de testosterona. Por este motivo, os genótipos ACTN3 RR / RX, devido ao efeito anabólico, possivelmente estão ligados a um maior aumento de massa muscular, principalmente pelo fato de possuir maior proporção de fibras musculares do tipo II, o que teoricamente é vantajoso para os esportes de força e potência e são mais responsivas à hipertrofia (Pimenta, 2012; Ahmetov et al., 2013; Arruda et al., 2014).

\subsection{O polimorfismo R577X do gene ACTN3: relação da genética com o tipo de fibra muscular}

Cada atleta, individualmente, possui respostas mecânicas e biológicas específicas que são expressas em sua modalidade. Desta forma, dentro do campo genético existe um rastreamento de "genes candidatos", que fornecem ao atleta sua possível performance em diferentes esportes (Spiering et al., 2008; Bueno Junior, \& Pereira, 2010). Como em questão, o polimorfismo dos homozigotos 577XX do gene ACTN3, presente em cerca de 18\% dos humanos (Mills et al., 2001) ocasiona total deficiência da proteína ACTN3, reduzindo a atividade do glicogênio muscular de forma anaeróbia, o que resulta na mudança em direção das vias oxidativas como fonte principal para utilização de energia. A presença da proteína ACTN3 está diretamente associada à melhora no desempenho de potência muscular (Eynon et al., 2009; Pasqua, Artioli, Pires, \& Bertuzzi, 2011; Araújo et al., 2018).

Para afirmar que o ACTN3 R tem relação com performance de velocidade e força, enquanto o polimorfismo R577X desse mesmo gene possui influência com o desenvolvimento de atletas que precisam resistência aeróbia, foram encontrados dados que comprovem essa tese. Um teste com treinamento excêntrico que foi aplicado em atletas jogadores de futebol que obtinham alelos RR, RX e XX, o estudo contou com a participação de 200 atletas profissionais de futebol de campo que compunham equipes inscritas na Confederação Brasileira de Futebol (CBF), o autor demonstrou que esses jogadores portadores do genótipo ACTN3/RR possuíam melhores tempos em testes de curtas distâncias, que se faz necessário maior potência (Pimenta, 2012).

Por fim, o treinamento excêntrico mostrou que os danos musculares em geral são mais elevados em indivíduos que possuíam o alelo XX após o exercício (Pimenta, 2012). A lesão muscular sofrida devido ao grande volume de exercícios intensos tem relação com o alto nível de cortisol plasmático. Esse hormônio pode estar ligado com um maior estresse muscular gerado após os treinos, agindo de forma catabólica, se opondo ao hormônio testosterona, que participa de efeitos anabólicos para a síntese proteica e de glicogênio muscular (Spiering et al., 2008).

Sendo assim, já foi identificado que indivíduos do grupo XX apresentaram maiores níveis de cortisol comparado com o grupo de alelos RR e RX. O quadro catabólico evidencia que, para indivíduos polimórficos, os treinamentos podem necessitar de um tempo maior para recuperação entre os estímulos, evitando possíveis lesões musculares, devido ao maior indício de danos a estes (Seto et al., 2011; Pimenta, 2012).

Em outro estudo realizado por Ahmetov et al. (2013), foram analisados 209 atletas de elite russos de diferentes modalidades. Ao comparar os indivíduos RR, RX e XX, também foram relatados menores níveis de testosterona nos indivíduos que apresentavam o alelo XX. Além disso, foi constado que os atletas que apresentavam o alelo R, exerciam maior potência durante as provas (Ahmetov et al., 2013).

Já no estudo realizado por Yang et al. (2003), foram separados três grupos diferentes, sendo ele composto por 107 atletas de elite velocistas/força, 194 atletas de elite de provas de resistência e 436 indivíduos não atletas. O alelo XX em relação aos esportes de força/potência foi localizado em apenas $8 \%$ do grupo masculino, e no grupo feminino, não foi encontrado em nenhuma atleta, sendo que praticantes de prova de resistência a frequência desse genótipo (XX) foi encontrado em $20 \%$ dentre os atletas masculinos e, em $29 \%$ das atletas do sexo feminino.

Já o alelo RR em esportes de resistência, estava presente em $28 \%$ dos atletas masculinos e $36 \%$ em atletas do grupo 
feminino. No que se tratava dos esportes de força, o alelo RR se encontra em 53\% do grupo masculino e $43 \%$ no grupo feminino. Analisando o genótipo RX, em atletas que praticavam esportes de força, 39\% dos homens obtinham esse genótipo, enquanto para as mulheres estava presente em 57\%. Para os atletas de resistência, foi encontrado em 52\% no grupo masculino e 35\% no feminino. No grupo controle, o gênero masculino teve frequência de 30\% do alelo RR, 54\% do alelo RX e 16\% para XX, enquanto o feminino foram 30\% para RR, 50\% para RX e 20\% para XX (Yang et al., 2003). No mesmo sentido, pesquisadores identificaram que não há entre os finalistas olímpicos, velocistas com o genótipo 577XX (Schaly, \& Nodari Júnior, 2013).

\section{Considerações Finais}

A expressão do gene ACTN3, presente nas fibras de contração rápida, sendo elas do tipo II, favorece o desempenho esportivo de atletas que exercem força/velocidade, sendo eles indivíduos portadores do alelo RR ou RX. O polimorfismo do ACTN3 causa inexistência da expressão desse gene, gerando um alelo mutante, chamado de XX.

Pessoas com o genótipo mutante possuem maior desempenho quando se trata de esportes de resistência aeróbia. A falta da $\alpha$-actinina-3 na musculatura do tipo II provoca redução da atividade de glicogênio-fosforilase em fibras doo tipo II, alterando as características dessas fibras, substituindo as vias energéticas metabólicas glicolíticas anaeróbias para oxidativas.

Porém, é de suma importância destacar que apenas um gene não é responsável por total sucesso de um atleta. Fatores extrínsecos, como por exemplo, treinamento adequado, rotina de descanso e alimentação, são indispensáveis para uma boa performance.

\section{Referências}

Abreu, P., Leal-Cardoso, J. H., \& Ceccatto, V. M. (2017). Adaptação do músculo esquelético ao exercício físico: considerações moleculares e energéticas. Revista Brasileira de Medicina do Esporte, 23 (1), 60-65. DOI https://doi.org/10.1590/1517-869220172301167371

Ahmetov, I. I., Gavrilov, D. N., Astratenkova, I. V., Druzhevskaya, A. M., Malinin, A. V., Romanova, E. E., \& Rogozkin, V. A. (2013). The association of ACE, ACTN3 and PPARA gene variants with strenght phenotypes in middle school-age chhildren. The Journal of Physiological Sciences, 63 (1), 79-85. DOI https://doi.org/10.1007/s12576-012-0233-8

Alencar, G. P. (2018). Relevância do treinamento de força e suas variáveis nos mais diversos objetivos. FIEP Bulletin, 88 (Especial), $341-344$. http://www.fiepbulletin.net/index.php/fiepbulletin/article/view/6010

Alencar, G. P., Gonçalves, J. L., Lima, L. E. M., \& Souza, A. F. (2017). Comparação das cargas de treinamento nos testes de repetições máximas e 1RM em indivíduos praticantes do treinamento de força. Revista Brasileira de Fisiologia do Exercício, 16 (3), 189-193. https://portalatlanticaeditora.com.br/index.php/revistafisiologia/article/view/1142

Alves, R. N., Costa, L. O. P., \& Samulski, D. M. (2006). Monitoramento e prevenção do supertreinamento em atletas. Revista Brasileira de Medicina do Esporte, 12 (5), 291-296. DOI https://doi.org/10.1590/S1517-86922006000500013

Araújo, M. C., Costa, A. S., Frota, C. M., Cortez, A. C. L., Gomes, A. C., \& Simões, H. G. (2018). Modulação genética da miostatina e do gene ACTN3 em hipertrofia e força muscular: uma revisão integrativa. Revista de Educação Física / Journal of Physical Education, 87 (1), 279-292. DOI https://doi.org/10.37310/ref.v87i1.255

Arruda, A. F. S., Aoki, M. S., Freitas, C. G., Drago, G., Oliveira, R., Crewthwer, B. T., \& Moreira A. (2014). Influence of competition playing venue on the hormonal responses, state anxiety and perception of effort in elite basketball athletes. Physiology \& Behavior, 130 (1), 1-5. DOI https://doi.org/10.1016/j.physbeh.2014.03.007

Berman, Y., \& North, K. N. (2010). A gene for speed: the emerging role of $\alpha$-actinin-3 in muscle metabolism. Physiology (Bethesda), 25 (4), 250-259. DOI https://doi.org/10.1152/physiol.00008.2010

Bompa, T. O. (2002). Periodização: teoria e metodologia do treinamento (4a ed.). São Paulo: Phorte.

Borges-Osório, M. R., \& Robinson, W. M. (2013). Genética humana (3a ed.). Porto Alegre: Artmed.

Bray, M. S., Hagberg, J. M., Pérusse, L., Rankinen, T., Roth, S. M., Wolfarth, B., \& Bouchard, C. (2009). The human gene map for performance and healthrelated fitness phenotypes: the 2006-2007 update. Medicine and Science in Sports and Exercise, 41 (1), 35-73. DOI https://doi.org/10.1249/mss.0b013e3181844179

Bueno Junior, C. R., \& Pereira, M. G. (2010). Biologia molecular como ferramenta no esporte de alto rendimento: possibilidades e perspectivas. Revista Brasileira de Ciências do Esporte, 31 (3), 231-249. DOI https://doi.org/10.1590/S0101-32892010000300016 
Castro-Ferreira, R., Fontes-Carvalho, R., Falcão-Pires, I., \& Leite-Moreira, A. F. (2011). Papel da titina na modulação da função cardíaca e suas implicações fisiopatológicas. Arquivos Brasileiros de Cardiologia, 96 (4), 332-339. DOI https://doi.org/10.1590/S0066-782X2011005000023

Cieszczyk, P., Sawczuk, M., Maciejewska-Karlowska, A., \& Ficek, K. (2012). ACTN3 R577X polymorphism in top-level Polish rowers. Journal of Exercise Science \& Fitness, 10 (1), 12-15. DOI https://doi.org/10.1016/j.jesf.2012.04.003

Dias, R. G., Pereira, A. C., Negrão, C. E., \& Krieger, J. E. (2007). Polimorfismos genéticos determinantes da performance física em atletas de elite. Revista Brasileira de Medicina do Esporte, 13 (3), 209-216. DOI https://doi.org/10.1590/S1517-86922007000300016

Druzhevskaya, A. M., Ahmetov, I. I., Astratenkova, I. V., \& Rogozkin, V. A. (2008). Association of the ACTN3 R577X polymorphism with power athlete status in Russians. European Journal of Applied Physiology, 103 (6), 631-634. DOI https://doi.org/10.1007/s00421-008-0763-1

Eynon, N., Duarte, J. A., Oliveira, J., Sagiv, M., Yamin C., Meckel, Y., \& Goldhammer, E. (2009). ACTN3 R577X polymorphism and Israeli top-level athletes. International Journal of Sports Medicine, 30 (9), 695-698. DOI https://doi.org/10.1055/s-0029-1220731

Farias, M. V., Barroso, P. P., Cavalcante, P. A., \& Parente, D. M. (2017). Influência de marcadores genéticos no desempenho atlético. Revista Brasileira de Prescrição e Fisiologia do Exercício, 11 (68), 626-630. http://www.rbpfex.com.br/index.php/rbpfex/article/view/1233

Guimarães, D. C. B., Oliveira, M. D. C., Rassi, T. O., Valadão, T. N., \& Borges Júnior, N. (2014). Princípios do treinamento esportivo. Lecturas: Educación Física y Deportes, 19 (199), 1-3. https://www.efdeportes.com/efd199/principios-do-treinamento-esportivo.htm

Hartl, D. L. (2008). Princípios de Genética de População (3a ed.). Ribeirão Preto: FUNPEC Editora.

Henesy, M. B., Britain, A. L., Zhu, B., Amable, L., Honkanen, R. E., Corbin, J. D., Francis, S. H., \& Rich, T. C. (2012). Calcineurin regulates homologous desensitization of 14 natriuretic peptide receptor-A and inhibits ANP-induced testosterone production in MA-10 cells. PLoS One, 7 (8), e41711. DOI https://doi.org/10.1371/journal.pone.0041711

Kasten, A. P. (2013). Aprendendo fisiologia do exercício: neuromuscular. Universidade Federal do Rio Grande do Sul. http://fisiofisioex.blogspot.com/2013/04/neuromuscular.html

Lek, M., \& North, K. N. (2010). Are biological sensors modulated by their structural acaffolds? The role of the structural muscle proteins $\alpha$-actinin-3 as modulators of biological sensor. FEBS Letters, 584 (14), 2974-2980. DOI https://doi.org/10.1016/j.febslet.2010.05.059

Lima, J. M., Serafim, P. V. P., Silva, I. D. C. G., \& Forones, N. M. (2006). Estudo do polimorfismo genético no gene p53 (códon 72 ) em câncer colorretal. Arquivos de Gastroenterologia, 43 (1), 8-13. DOI https://doi.org/10.1590/S0004-28032006000100005

MacArthur, D. G., \& North, K. N. (2005). Genes and human elite athletic performance. Human Genetics, 116 (5), 331-339. DOI https://doi.org/10.1007/s00439-005-1261-8

MacArthur, D. G., Seto J. T., Raftery, J. M., Quinlan, K. G., Huttley, G. A., Hook, J. W., Lemckert, F. A., Kee, A. J., Edwards, M. R., Berman, Y., Hardeman, E. C., Gunning, P. W., Easteal, S., Yang, N., \& North, K. N. (2007). Loss of ACTN3 gene function alters mouse muscle metabolism and shows evidence of positive selection in humans. Nature Genetics, 39 (10), 1261-1265. DOI https://doi.org/10.1038/ng2122

Mills, M., Yang, N., Weinberger, R., Woude, D. L. V., Beggs, A. H., Easteal, S., \& North, K. (2001). Differential expression of the actin-binding proteins, alpha-actinin-2 and -3, in different species: implications for the evolution of functional redundancy. Human Molecular Genetics, 10 (13), 1335-1346. DOI https://doi.org/10.1093/hmg/10.13.1335

Neeser, K. J. (2009) The Genes who make the Champions: “Can Genes predict Athletic Performance?”. Journal of Sports Science and Health, 10 (Suppl.), 106-132. https://www.spsc.chula.ac.th/backupnew/web_older/main2007/academic/pdf10sp/10sp-13.pdf

Netto, Z. C. O. (2014). Estudo molecular dos genes alfa actinina 3 e ECA I/D em atletas de esportes de combate, artes marciais e lutas de alto rendimento: ênfase em luta de percussão (Dissertação de Mestrado). Universidade Tecnológica Federal do Paraná, Curitiba, PR, Brasil. http://repositorio.utfpr.edu.br/jspui/handle/1/1020

Paiva, E. M., \& Carlesso, J. P. P. (2018). The importance of the psychologist's role today: experience report. Research, Society and Development, 8 (3), e283798. DOI https://doi.org/10.33448/rsd-v8i3.798

Paiva, M. R., Rodrigues, G. C. G., Pereira, T. T., Alencar, G. P., Lima, L. E. M., Krug, A. L. O., \& Souza, A. F. (2019). Respostas agudas da pressão arterial em exercícios básicos do treinamento de força. Revista Brasileira de Fisiologia do Exercício, 18 (1), 3-8. DOI https://doi.org/10.33233/rbfe.v18i1.2532

Pasqua, L. A., Artioli, G. G., Pires, F. O., \& Bertuzzi, R. (2011). ACtn3 e desempenho esportivo: um gene candidato ao sucesso em provas de curta e longa duração. Revista Brasileira de Cineantropometria e Desempenho Humano, 13 (6), 477-483, 2011. DOI https://doi.org/10.5007/1980-0037.2011v13n6p477

Pimenta, E. M. (2012). Polimorfismos genéticos para alfa actinina 3 e sua relação com dano muscular e capacidades funcionais em atletas de futebol (Tese de Doutorado). Universidad de León, Léon, Espanha. DOI http://dx.doi.org/10.18002/10612/3175

Rebbeck, T. R., Spitz, M., \& Wu, X. (2004). Assessing the function of genetic variants in candidate gene association studies. Nature Reviews Genetics, 5 (8), 589-597. DOI https://doi.org/10.1038/nrg1403

Rother, E. T. (2007). Revisão sistemática X Revisão narrativa. Acta Paulista de Enfermagem, 20 (2), V-VI. DOI https://doi.org/10.1590/S010321002007000200001

Schaly, D., \& Nodari Júnior, R. J. (2013). Perfil dermatoglífico e determinação da frequência genotípica da actn3 em atletas promessas olímpicas. Unoesc \& Ciência - ACBS, 4 (1), 27-38. https://portalperiodicos.unoesc.edu.br/acbs/article/view/2673 
Research, Society and Development, v. 10, n. 14, e519101422235, 2021

(CC BY 4.0) | ISSN 2525-3409 | DOI: http://dx.doi.org/10.33448/rsd-v10i14.22235

Scott, W., Stevens, J., \& Binder-Macleod, S. A. (2001). Human skeletal muscle fiber type classifications. Physical Therapy, 81 (11), 1810-1816. DOI https://doi.org/10.1093/ptj/81.11.1810

Seto, J. T., Lek, M., Quinlan, K. G. R., Houweling, P. J., Zheng, X. F., Garton, F., MacArthur, D. G., Raftery, J. M., Garvey, S. M., Hauser, M. A., Yang, N., Head, S. I., \& North, K. N. (2011). Deficiency of $\alpha$-actinin-3 is associated with increased susceptibility to contraction-induced damage and skeletal muscle remodeling. Human Molecular Genetics, 20 (15), 2914-2927. DOI https://doi.org/10.1093/hmg/ddr196

Silva, A. A., Justina, L. A. D., Scheifele, A., \& Schneider, E. M. (2020). Analyses of the concepts of genotype and phenotype in course books from 1950 to nowadays. Research, Society and Development, 9 (7), e220973849. DOI https://doi.org/10.33448/rsd-v9i7.3849

Sjöblom, B., Salmazo, A., \& Djinović-Carugo, K. (2008). Alpha-actinin structure and regulation. Cellular and Molecular Life Sciences, 65 (17), $2688-2701$. DOI https://doi.org/10.1007/s00018-008-8080-8

Spiering, B. A., Kraemer, W. J., Anderson, J. M., Armstrong, L. E., Nindl, B. C., Volek, J. S., \& Maresh, C. M. (2008). Resistance exercise biology: manipulation of resistance exercise programme variables determines the responses of cellular and molecular signalling pathways. Sports Medicine, 38 (7), 527-540. DOI https://doi.org/10.2165/00007256-200838070-00001

Strachan, T., \& Read, A. (2016). Genética Molecular Humana (4a ed.). Porto Alegre: Artmed.

Tanisawa, K., Wang, G., Seto, J., Verdouka, I., Twycross-Lewis, R., Karanikolou, A., Tanaka, M., Borjesson, M., Luigi, L. D., Dohi, M., Wolfarth, B., Swart, J., Bilzon J. L. J., Badtieva, V., Papadopoulou, T., Casasco, M., Geistlinger, M., Bachl, N., Pigozzi, F., \& Pitsiladis, Y. (2020). Sport and exercise genomics: the FIMS 2019 consensus statement update. British Journal of Sports Medicine, 54 (16), 969-975. DOI https://doi.org/10.1136/bjsports-2019-101532

Trindade, M. C. D. S., Rodrigues, B. C., Rodrigues, R. F. A., \& Almeida, D. M. P. F. (2017). A influência genética na performance esportiva. Revista Interdisciplinar Ciências e Saúde, 4 (2), 113-120. https://revistas.ufpi.br/index.php/rics/article/view/5980

Tubino, M. J. G. (1979). Metodologia científica do treinamento desportivo. São Paulo: Ibrasa.

Vincent, B., Bock, K., Ramaekers, M., Eede, E. V. D., Leemputte, M., Hespel, P., \& Thomis, M. A. (2007). ACTN3 (R577X) genotype is associated with fiber type distribution. Physiological Genomics, 32 (1), 58-63. DOI https://doi.org/10.1152/physiolgenomics.00173.2007

Wood, E. J. (1995). The encyclopedia of molecular biology. Biochemical Education, 23 (2), 105. DOI https://doi.org/10.1016/0307-4412(95)90659-2

Yang, N., MacArthur, D. G., Gulbin, J. P., Hahn, A. G., Beggs, A. H., Easteal, S., \& North, K. (2003). ACTN3 genotype is associated with human elite athletic performance. The American Journal of Human Genetics, 73 (3), 627-631. DOI https://dx.doi.org/10.1086\%2F377590

Zonatto, H. A. (2018). Análise do polimorfismo r577x do gene alfa actina 3 como possível preditor de desempenho físico em mulheres ultramaratonistas (Dissertação de Mestrado). Universidade Tecnológica Federal do Paraná, Curitiba, PR, Brasil. https://repositorio.utfpr.edu.br/jspui/handle/1/3843 